\title{
Joubert's syndrome with retinal dysplasia: neonatal tachypnoea as the clue to a genetic brain-eye malformation
}

\author{
M D KING, J DUDGEON, AND J B P STEPHENSON \\ Fraser of Allander Unit (Paediatric Neurology) and Department of Ophthalmology, Royal Hospital for Sick \\ Children, Glasgow
}

SUMMARY Five children with features of Joubert's syndrome and Leber's amaurosis are described. The presenting symptoms were panting tachypnoea in the newborn, prolonged apnoeic attacks in the neonatal period (in both of identical twins), global developmental delay, and failure to develop vision. Three children had multiple hemifacial spasms, such as have been seen in Joubert's syndrome, and the same three had cystic dysplasia of the kidneys. Necropsy confirmed the retinal and renal pathology, together with agenesis of the vermis and brainstem dysgenesis in the identical twins. It is concluded that a gene for Leber's amaurosis may commonly manifest itself as the specific hind brain malformation underlying Joubert's syndrome.

In infants with respiratory irregularities (especially rapid panting), hemifacial spasms, or developmental delay, absence of the cerebellar vermis should be specifically sought by ultrasound and computed tomography, and the electroretinogram measured, whether or not impaired vision is clinically evident.

Joubert's syndrome ${ }^{1-15}$ comprises episodic panting tachypnoea and jerky eye movements in the neonatal period with subsequent ataxia, dysequilibrium, and mental handicap accompanied by agenesis of the cerebellar vermis and brainstem malformation. ${ }^{16}$ Leber's amaurosis (congenital retinal blindness) is an autosomal recessive disorder characterised by visual impairment, normal optic fundus in infancy, and miniscule electroretinogram response: cerebral and renal malformations often coexist. ${ }^{17} \mathrm{We}$ describe five children with features of both disorders (proved at necropsy in two children) to alert paediatricians to specific cerebral imaging and retinal function studies in neonates with unexplained panting tachypnoea.

\section{Case reports}

Case one. A boy, the first child of healthy, unrelated Scottish parents (mother aged 34 years, father 27 years), was born at term by elective caesarean section, after an uneventful pregnancy. His birth- weight was $2980 \mathrm{~g}$ and Apgar scores were 7 at one minute and 9 at five minutes. He was admitted to the paediatric department because of an abnormal respiratory pattern consisting of episodes of tachypnoea (200 per minute) of up to two minutes duration, alternating with apnoea (10 to 35 seconds), without colour change or alteration in heart rate. The baby's head circumference was 34 $\mathrm{cm}$, the facies was odd (small eyelid aperture, flat upturned nose), and the tongue protruded (Fig. 1). Jerky, rapid, irregular conjugate eye movements and general hypotonia were present. The tachypnoea was exacerbated when the baby was stimulated but diminished during sleep. Frequent hemifacial spasms associated with pallor, sweating, and prolonged apnoea (up to 40 seconds) were observed.

The following investigations were normal: full blood count, serum urea, electrolytes, liver function tests, thyroid studies, pyruvate, lactate, ammonia, $\mathrm{pH}, \mathrm{PcO}_{2}$, bicarbonate, free fatty acids, chromosome studies, plasma and urinary amino acids, and urinary organic acids. Bacteriological and viral 


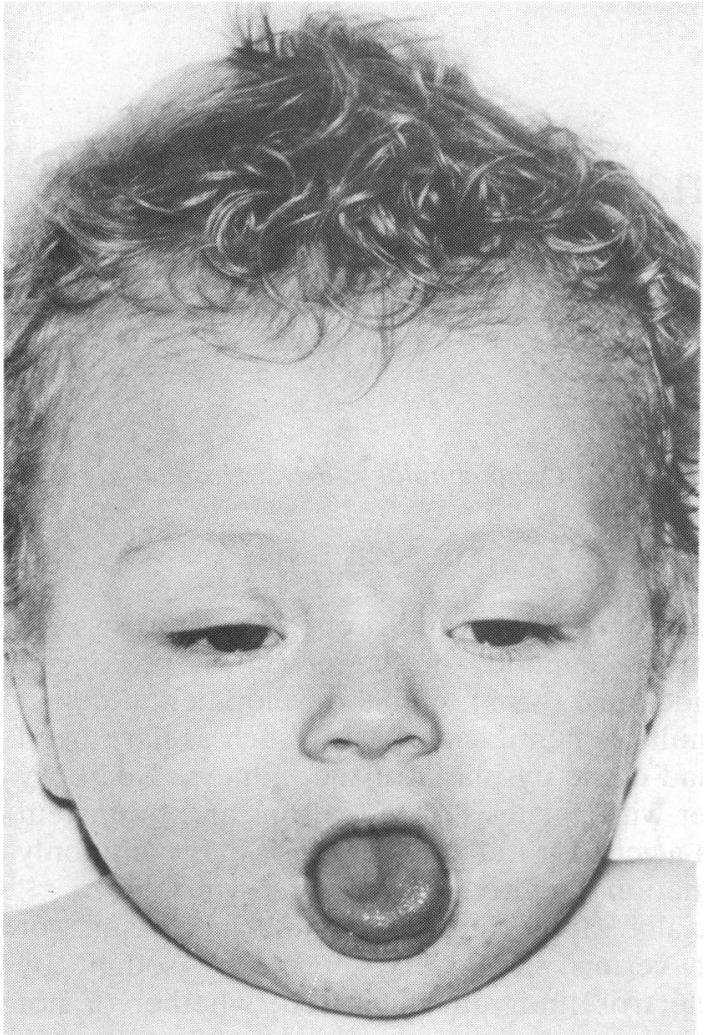

Fig. 1 Patient in case 1 aged 8 months showing characteristic tongue protrusion. He had a flat upturned nose and small eyelid apertures. cultures of blood, cerebrospinal fluid, and urine were negative. In addition, the electroencephalogram, brainstem auditory evoked responses, electrocardiogram, and skull and chest radiographs were normal. The respiratory pattern was attributed to 'immaturity of the respiratory centres' and the infant was discharged home at 3 weeks of age.

At 3 months of age the infant was visually inattentive and was referred to this hospital. The physical findings were as described at birth. Sleep stages were difficult to identify because of tachypnoea and abnormal eye movements, but tachypnoea and hemifacial spasms seemed to occur while awake and during rapid eye movement and non-rapid eye movement sleep, whereas prolonged apnoea occurred only during non-rapid eye movement sleep. Pupils were of normal size and reacted to light. Fundoscopy showed normal discs and maculae with some thinning of the retinal pigment layer and exposure of the underlying choroidal vessels.

Joubert's syndrome was suspected and a computed tomogram showed an enlarged fourth ventricle extending higher than usual with a reduced density area extending posteriorly, confirming vermal agenesis (Fig. 2). The electroretinogram was unrecordable with skin electrodes: with corneal electrodes the following recordings were made:-5 $\mu \mathrm{v}$ mesopic b wave (normal 30 to $70 \mu \mathrm{v}$ ); a $5 \mu \mathrm{v} 3$ minute dark adapted scotopic b wave (normal 140 to $200 \mu \mathrm{v}) ;$ a $6 \mu \mathrm{v} 6$ minute dark adapted scotopic b wave (normal 150 to $250 \mu \mathrm{v}$ ). Visual evoked responses were of small amplitude and delayed $(200 \mathrm{~m}$ seconds to $\mathrm{P} 1)$. This gross attenuation of the
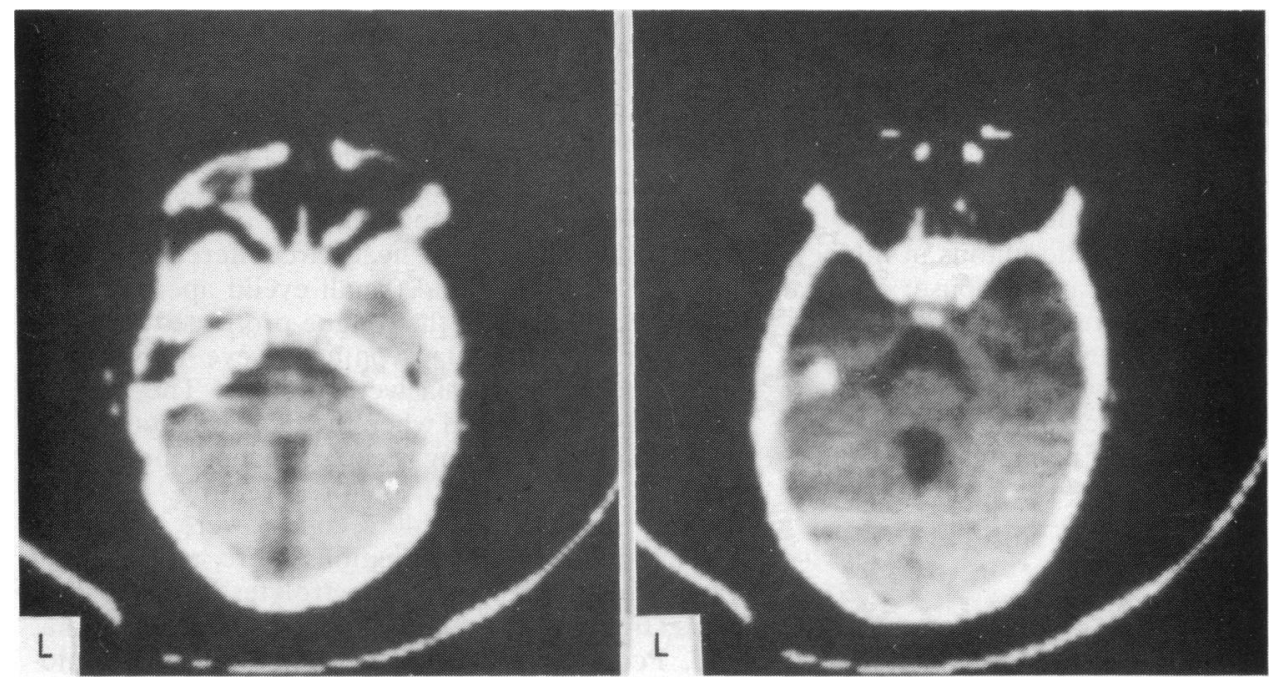

Fig. 2 Patient in case 1: serial computed tomograms of the posterior fossa showing an enlarged fourth ventricle with an area of low attenuation posteriorly consistent with vermal agenesis. 
electroretinogram confirmed retinal dysplasia. Intravenous pyelogram showed multiple small cysts biliterally.

At the time of writing the child is 3 years old and is hypotonic, sits unsupported, but is unable to crawl or speak. He has severe visual impairment, episodic hyperpnoea (although less strikingly), and hemifacial spasms. The electroretinographic findings are unchanged.

Cases 2 and 3. Cases 2 and 3, both boys, were monozygous twins (proved by zygosity testing) born to healthy unrelated Scottish parents aged 34 and 35 years. Two previous siblings had died of primary apnoea in the neonatal period. A boy born at term had tachypnoea (130 per minute) and apnoea; despite ventilation he died at 48 hours of age. Necropsy showed polycystic kidneys, pulmonary haemorrhage, and a dilated fourth ventricle. A second infant, a girl, failed to respond to resuscitation at birth. At necropsy polycystic kidneys, pulmonary haemorrhage, and a dilated fourth ventricle were found. The appearance of the cerebellar vermis was not documented in either infant. Chromosome studies were normal and viral titres were negative in both infants. Another sibling (a boy) is alive and healthy.

The twin pregnancy was uncomplicated until the onset of premature labour at 34 weeks' gestation. Both twins were delivered by low cavity forceps. Clinical, biochemical, radiological, ultrasonic, electrophysiological, and necropsy findings were virtually identical in both and a single description follows.

Case 2

Apgar scores were 5, 9, and 10 at one, five, and 10 minutes respectively. Birthweight was $2320 \mathrm{~g}$ and head circumference $32.5 \mathrm{~cm}$. Irregular, panting respirations, alternating 'facial palsy', dysmorphic facies, and enlarged right kidney were noted immediately. On day two apnoeic attacks with cyanosis and bradycardia lasting up to three minutes developed and apparently were terminated by bag and mask ventilation.

Electrolytes, glucose, haemoglobin, cerebrospinal fluid examination, and chest radiograph were normal and cultures of cerebrospinal fluid blood and urine were sterile. The abnormal breathing pattern was attributed to prematurity, and aminophylline suppositories were given without effect on the frequency or duration of apnoea. The infant was discharged home at age 4 weeks.

The infant was admitted to this hospital at age 9 weeks, after frequent prolonged apnoeic attacks. On examination, head circumference was $36.5 \mathrm{~cm}$ (50th centile) and fontanelles were wide. There was a small vascular malformation of the skin over the upper occiput. Jerky, irregular conjugate eye movements, protruding tongue, dysmorphic facies, alternating hemifacial spasms (Fig. 3), and tachypnoea (150 per minute) with apnoea up to three minutes duration, noticeable head lag, hypotonia, and bilateral syndactyly of the second and third toes were present.

A clinical diagnosis of Joubert's syndrome was made and on transfontanelle ultrasound scanning of the posterior fossa, the normal pyramidal fourth ventricle was shown to be replaced by an oblong transonic area above the cerebellum on both longitudinal and transverse scans, suggesting agenesis of the vermis of the cerebellum (Fig. 4).

As ultrasound findings in Joubert's syndrome have not been described previously, computed tomography was performed. An enlarged fourth ventricle extending higher than usual, with an atrophic area in the region of the cerebellar vermis, supporting vermal agenesis was shown (Fig. 5). Polygraphic recordings showed tachypnoea and hemifacial spasms while awake and during rapid and non-rapid eye movement sleep, but apnoea occurred during non-rapid eye movement sleep only.

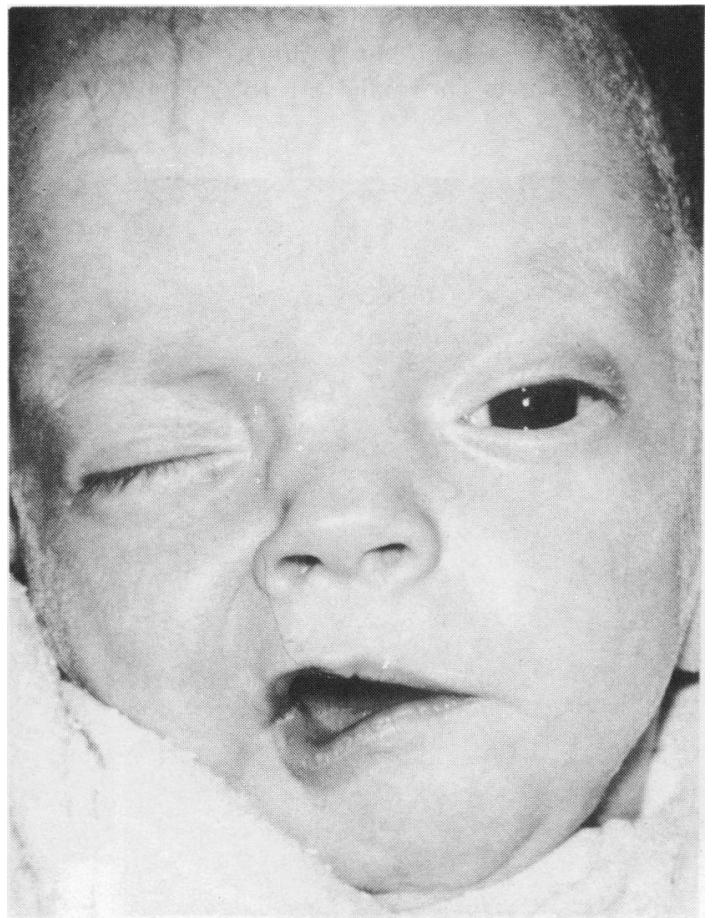

Fig. 3 Patient in case 2 aged 9 weeks showing right hemifacial spasm. 


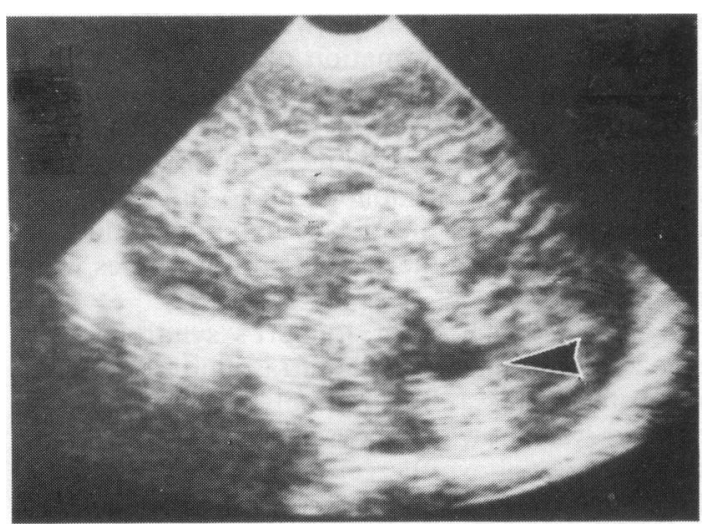

Fig. 4 Patient in case 2: sagittal midline ultrasound brain scan showing a large transonic area above the fourth ventricle due to absence of the cerebellar vermis.

Ultrasound examination of the kidneys and intravenous pyelogram showed cystic changes in the right kidney; the left kidney was not visualised.

At 12 weeks of age the infant was visually unresponsive. Fundoscopy showed slight accentuation of pigmentation in an equatorial distribution suggesting retinal aplasia of Leber's amaurosis. The electroretinogram, recorded with corneal electrodes, was grossly abnormal; a $10.5 \mu \mathrm{v}$ mesopic $\mathrm{b}$ wave (normal 30 to $70 \mu \mathrm{v}$ ) and $10 \mu \mathrm{v} 10$ minute scotopic b wave (normal 150 to $250 \mu \mathrm{v}$ ) were recorded confirming Leber's amaurosis. Chromosomes, determined by Giemsa banding, were normal. The infant was discharged home at 4 months of age but died two weeks later after an episode of prolonged apnoea.

The main findings at necropsy examination were in the skull, brain, eyes, liver, and kidneys. There was a small circular midline defect ( $3 \mathrm{~mm}$ diameter) in the upper occiput containing meningeal tissue only. There was a small vascular malformation of the skin and subcutis overlying the occult meningocele. The base of the brain showed the unci to lie more closely together than normal, completely overhanging the mammillary bodies. The brain stem and the cranial nerves were normal externally, but on section the olives were unusually prominent. The cerebellum $(90 \mathrm{~g})$ had an unusual shape, being rounded when viewed from above. The cerebellar hemispheres were applied to each other with complete absence of the vermis and a midline cleft. Apart from agenesis of the vermis, the cerebellum was unremarkable.

The histological findings in the cervico-medullary junction, cerebellum, pons, thalmus, mid-brain, and cerebral hemisphere were unremarkable. In the medulla the olives showed a striking hyperplasia of neurones with roughly $30 \%$ more neurones by comparison with normal specimens. The tractus solitarius could not be identified in two levels of medulla and two levels of pons. In some situations in
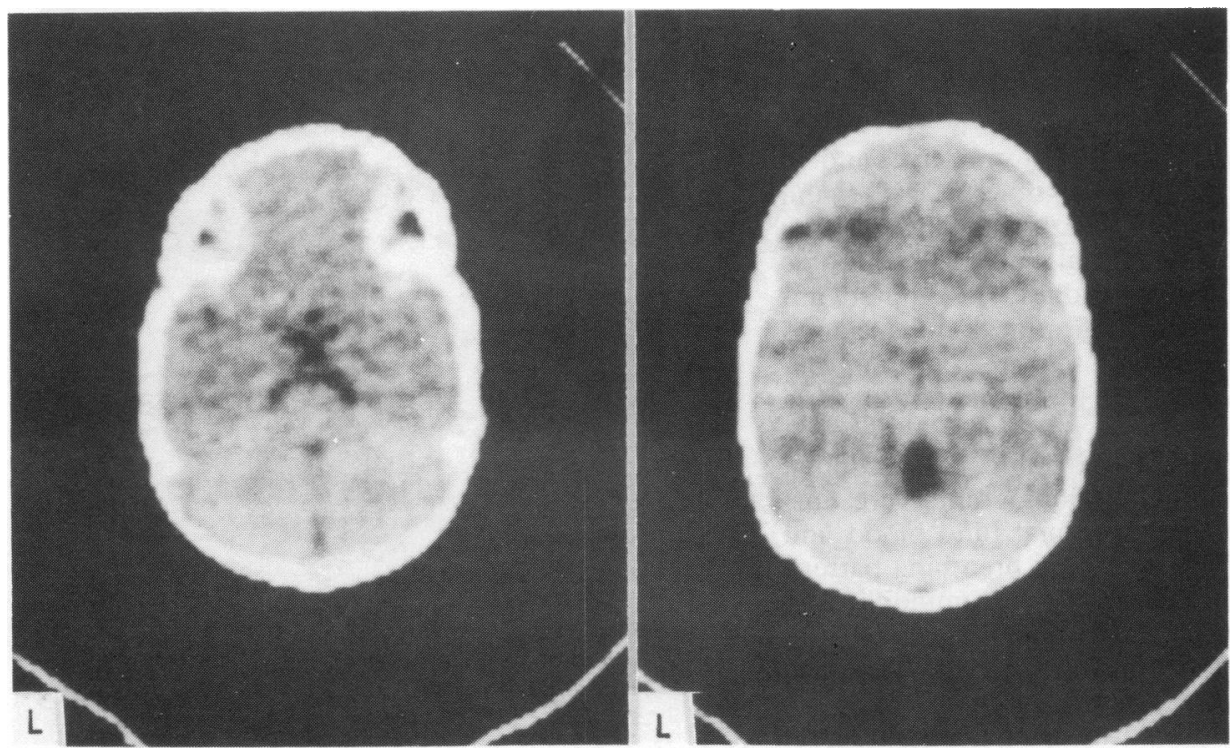

Fig. 5 Patient in case 2: serial computed tomograms showing an enlarged fourth ventricle with a reduced density area posteriorly, consistent with vermal agenesis. 
which the tract might be expected to be seen, there were small collections of neurones which could not be readily classified as belonging to any other nuclear system.

The only macroscopic abnormality in the eyes was a fine pigmentary disturbance in the mid-periphery of each eye, with a broad pale tongue radiating from the disc and macula. The anterior segments were unremarkable. There was a selective reduction in the number of nuclei in the mid-peripheral and posterior outer nuclear layer and in the midperiphery there was an appreciable reduction in the melanosome content of short segments of the retinal pigmented epithelium. Thus, there was definite evidence of geographical tapetoretinal degeneration.

The liver (244 g) was slightly enlarged. The capsular and the cut surfaces showed a uniformly fine granular appearance but there was no cyst formation. There was a diffuse increase in the size of the portal tracts with an interconnecting network of bile ductules, some of which were dilated. The hepatocytes were unremarkable.

The kidneys were both abnormal. The left kidney $(0.9 \mathrm{~g})$ was a tiny dysplastic mass in the normal renal site associated with atresia of the upper half and hypoplasia of the lower half of the ureter. The right kidney $(29 \mathrm{~g})$ showed exaggerated fetal lobulation and several thin walled cysts (up to $3 \mathrm{~mm}$ diameter) projecting from the subcapsular surface, mainly at the poles. The cut surface showed disorganisation of the normal corticomedullary architecture. The pelvicalyceal system and the ureter were essentially normal. The left kidney showed severe dysplastic change with abnormal tubules, microcysts, and heterotopic cartilage, but no normal renal parenchyma. In the right kidney there was considerable glomerulotubular differentiation but widespread dysplastic change varying from mild to severe.

\section{Case 3}

After the death of his twin at home, this infant was readmitted to hospital. Profound hypotonia, no psychomotor development or visual responses, hemifacial spasms (Fig. 6), jerky eye movements, and episodic tachypnoea and apnoea were present until the baby's death at 13 months of age during a prolonged apnoeic episode.

Case 4. A girl, the first child of healthy, unrelated Scottish parents (mother aged 22 years, father 34 years), was delivered by elective caesarean section for breech position after premature rupture of membranes, at 36 weeks' gestation. Her birthweight was $2960 \mathrm{~g}$ and head circumference was $34 \mathrm{~cm}$.

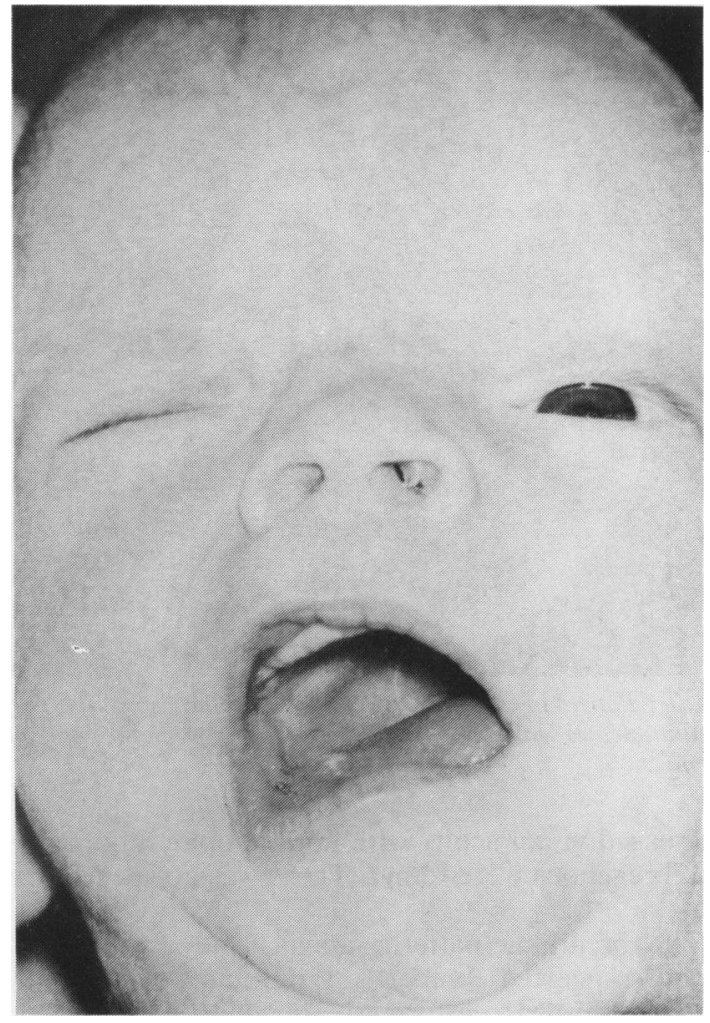

Fig. 6 Patient in case 3 aged 9 weeks showing right hemifacial spasm superficially ressembling left facial weakness.

Apgar scores were 8 at one minute and 9 at five minutes. The infant was admitted to the neonatal unit because of tachypnoea (100 per minute), for which no cause was found. The tachypnoea diminished over the first week and the infant was discharged home.

At 6 months of age the infant was referred to hospital because of floppiness and suspected poor vision. Poor head control, mild hypotonia, brisk lower limb reflexes, tongue protrusion, absent visual following or fixation, and jerky eye movements were found. A diagnosis of non-specific global delay was made. The child smiled at age 4 months, reached out for objects at 14 months, and sat unsupported at 16 months.

At 18 months she was referred to this hospital. On examination there was constant tongue protrusion with episodic tachypnoea (80 to 100 per minute). The child sat unsupported but there was noticeable truncal ataxia and increased tone and reflexes in the lower limbs. Jerky ocular pursuit movements and 


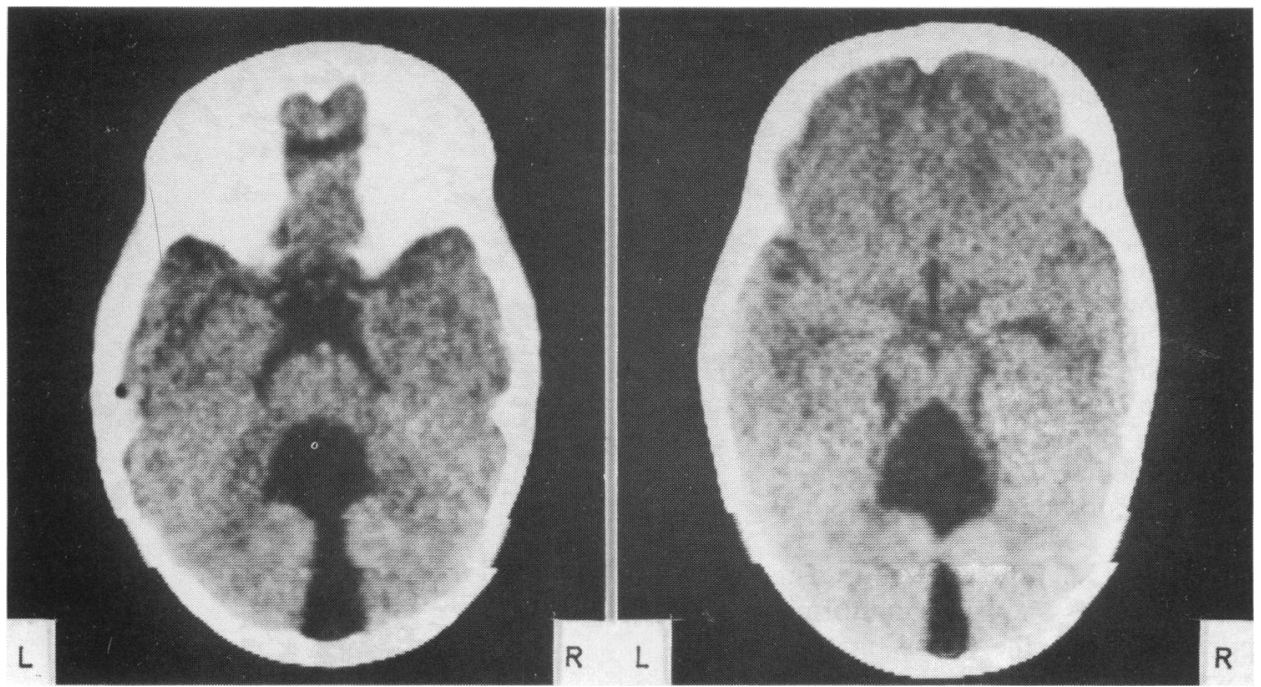

Fig. 7 Patient in case 4: serial computed tomograms of posterior fossa showing dilated fourth ventricle which communicates with a posterior cystic area between the cerebellar hemispheres, consistent with agenesis of the cerebellar vermis.

decreased visual acuity with normal optic fundi and pupil reactions were found. There was no speech or play.

The breathing pattern, ataxia, and eye movements suggested Joubert's syndrome. Computed tomography was performed, showing dilatation of the fourth ventricle which communicated with a posterior cystic area between the cerebellar hemispheres (Fig. 7) consistent with agenesis of the cerebellar vermis. The electroretinogram showed considerably reduced values: mesopic b wave $6 \mu \mathrm{v}$ (normal 30 to $70 \mu \mathrm{v}$ ); 5 minute scotopic b wave $16 \mu \mathrm{v}$ (normal 150 to $250 \mu \mathrm{v}$ ). Ultrasonography of the kidneys showed no abnormality. Chromosomes, determined by Giemsa banding, were normal.

Case 5. A girl, the first child of healthy, unrelated Scottish parents aged 24 and 26 years, was born at term by normal delivery. She weighed $2660 \mathrm{~g}$ and her head circumference was $36 \mathrm{~cm}$. She was admitted to the neonatal unit after episodic panting tachypnoea (120 per minute) which was exacerbated when she was stimulated. No cause was found for the tachypnoea which was less prominent after 4 weeks of age. There was a vascular malformation of the skin overlying the occiput.

At 3 months of age the infant was not following or fixating with the eyes and was referred to this hospital. Her respiratory pattern was normal, but she had hypotonia, head lag, jerky eye movements, tongue protrusion, and no visual fixation or following. Pupils were of normal size and reacted to light.
The optic fundi were normal. The electroretinogram was unrecordable. Computed tomography showed the fourth ventricle extending higher than usual with a low density area in the region of the cerebellar vermis. Intravenous pyelogram showed bilateral cystic kidneys. Chromosomes were normal.

All milestones were delayed. The child walked at $4 \frac{1}{2}$ years; at 7 years she is blind, hypotonic, and walks with broad based ataxic gait. There is no speech, constant tongue protrusion, and severe mental retardation. The electroretinogram is absent.

\section{Discussion}

In 1981 we speculated that the abnormal eye movements and poor visual attention in our patient in case 1 might have a peripheral rather than a central mechanism. The electroretinogram was sought and found to be grossly deficient (confirmed at follow up). A child previously coded as having Leber's amaurosis was found to have a neonatal history and other findings typical of Joubert's syndrome (case 5). At this time the Japanese report of the coincidence of Joubert's syndrome and Leber's amaurosis ${ }^{5}$ was received. We then alerted others in the field to this connection from which followed the observations of Aicardi et al. ${ }^{15}$ The clinical and pathological findings in the twins (cases 2 and 3) confirmed the association. The patient in case 4 was then referred to us for electroretino- 


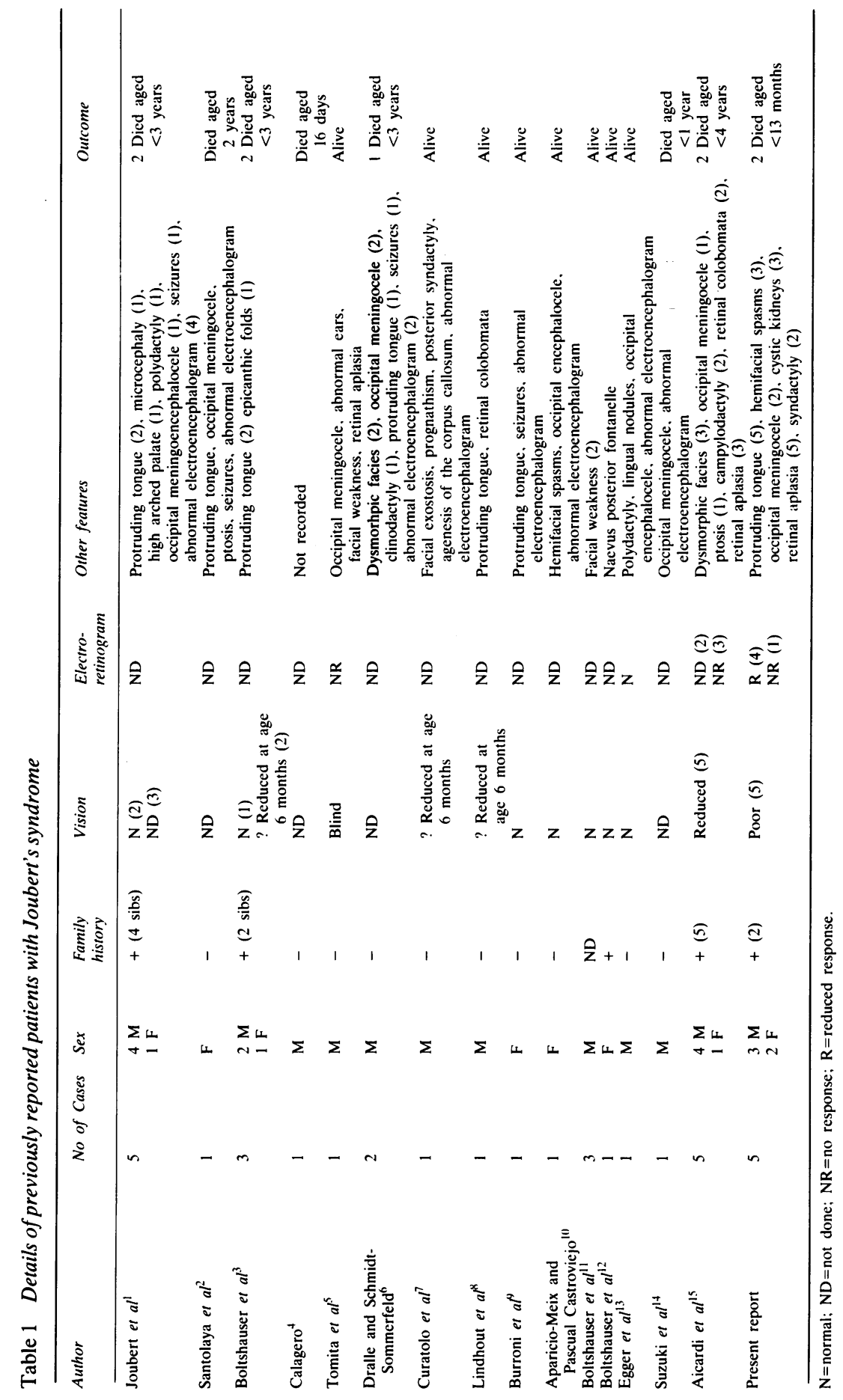


graphic investigation once the diagnosis of Joubert's syndrome had been suspected.

The five cases reported here illustrate the variability in presentation of Joubert's syndrome-panting tachypnoea at birth (case 1); prolonged apnoeic attacks, tachypnoea, and hemifacial spasms in the neonatal period (cases 2 and 3); global developmental delay (case 4) and failure to develop vision (case 5). Although the clinical hallmark of the syndrome is neonatal episodic hyperpnoea resembling the panting of a dog, the significance of this was not recognised at birth in any of these patients. In addition, the abnormal respiratory pattern tends to wane with age, thus the importance of a detailed neonatal history in older children presenting with the features described.

The necropsy findings in two cases were comparable with published pathological reports of Joubert's syndrome $^{16}$ and Leber's amaurosis. ${ }^{18-2.3}$

The cases of Joubert's syndrome reported to date are summarised in Table 1. All showed panting tachypnoea at birth and partial or total agenesis of the cerebellar vermis.

Conflicting reports have been published ${ }^{6} 1215$ on the relation between the respiratory pattern and sleep stages, probably due to the difficulty in identification of sleep phases in these infants. It has been suggested ${ }^{16}$ that the respiratory irregularity may be attributable to anomalies of the solitary tract (tractus solitarius) and gracile nuclei seen at necropsy, as these are thought to be important as relay centres for a variety of chemical and sensory stimuli that affect ventilation.

Neuroradiological studies show an unusually shaped fourth ventricle and a midline defect in the posterior fossa compatible with vermal agenesis. There is considerable variation in the size and shape of the fourth ventricle and cisterna magna even within the same family. ${ }^{15}$ The use of ultrasonography in Joubert's syndrome has not been reported previously.

Variable features described in Joubert's syndrome include dysmorphic facies (eight cases), 1 5-7 15 occipital meningocele (six cases), 2561415 occipital encephalocele (three cases) ${ }^{1} 101.3$ seizures (five cases), 1269 10 electroencephalographic abnormalities (13 cases), 12679101.314 skeletal abnormalities (seven cases), ${ }^{1} 671315$ and agenesis of the corpus callosum (one case). ${ }^{7}$ Hemifacial spasms, seen in three patients in this report, have only been described once previously, ${ }^{10}$ but we suspect that these spasms were responsible for the 'facial palsy' described in three further cases. ${ }^{1} 11$

Malformation syndromes exhibiting some of the features of Joubert's syndrome, but distinguishable clinically and pathologically, are shown in Table 2.

Despite the findings of abnormal eye movements in most cases, detailed ophthalmological assessment has been reported in only seven. ${ }^{5} 15$ Four of the remainder were not following or fixating at 6 months of age,${ }^{3715}$ one died aged 18 days, ${ }^{4}$ in six $^{12614}$ no reference was made to vision, and in 10 it was said to be 'normal'. $3911(-13$ The ocular abnormalities reported are retinal colobomata ${ }^{815}$ and Leber's amaurosis. ${ }^{5}{ }^{15}$ The latter association may have been underestimated in earlier reports where electrophysiological studies were not performed. Clinical assessment of visual acuity is difficult in mentally retarded patients: in Leber's amaurosis visual impairment may be mild and fundus appearance normal in infancy while the electroretinogram is grossly attenuated. ${ }^{17}$ The electroretinogram has been unrecordable or miniscule in nine of the 10 cases in which it has been measured (Table 1): the

Table 2 Malformations having some features in common with Joubert's syndrome

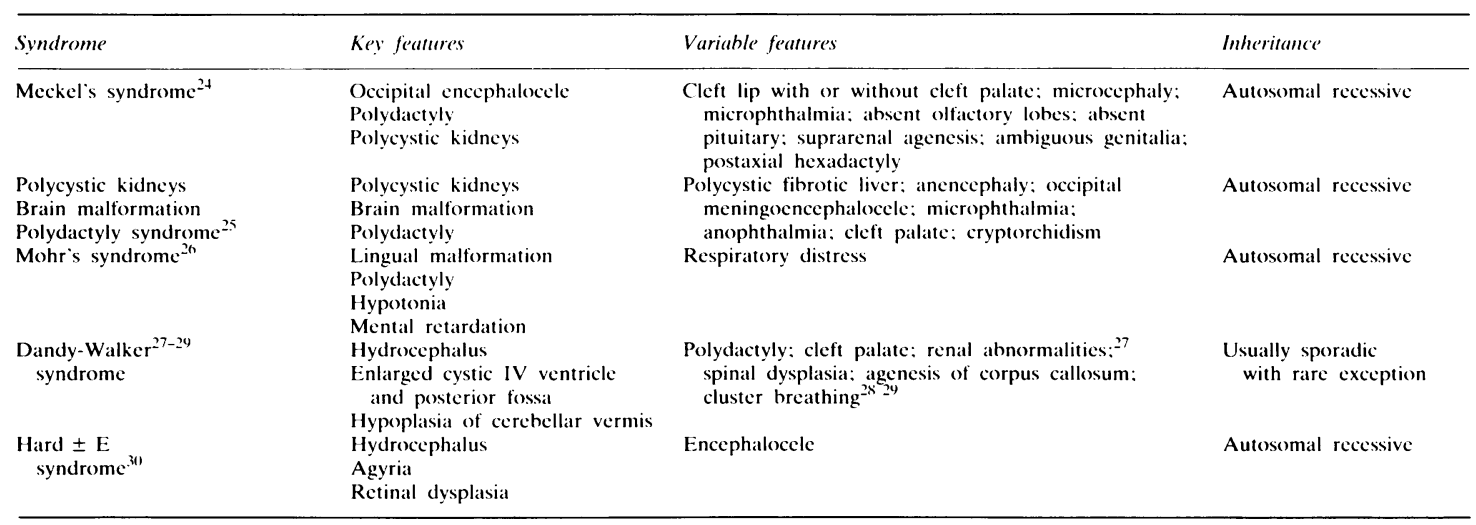


exception ${ }^{13}$ was a child with polydactyly and lingual malformation who had certain resemblances to Mohr's syndrome. ${ }^{26}$

Although some workers ${ }^{31}$ have suggested that maturation of the response to light is not attained until the end of the first year, in our experience and that of others 3233 the electroretinogram is easily recordable in infants with normal vision and is of sufficient amplitude, leaving no scope for confusion with Leber's amaurosis.

The association of neurological abnormalities and cystic kidneys with Leber's amaurosis is well recognised. ${ }^{17} 22$ 34-38 Neurological features include epilepsy, ${ }^{17} 2234-37$ mental retardation, ${ }^{17} 2234-37$ cerebral diplegia, ${ }^{37}$ diffuse cerebellar hypoplasia, ${ }^{17} 36$ and aplasia of the cerebellar vermis. ${ }^{36}$ The last association cannot be explained on embryological grounds: the lips of the rostral rhombencephalon fuse to form the vermis between 40 and 50 days' gestation ${ }^{32}$ dating the teratogenic event in vermal agenesis to that period, whereas Leber's amaurosis is thought to be a disorder of the late stages of growth and differentiation. This theory is supported by the finding that in Leber's amaurosis all three nuclear layers and both plexiform layers are well developed ${ }^{39}$ and there is some differentiation of cones, suggesting that differentiation reaches at least 18 weeks before development is interrupted. ${ }^{40}$

The recurrence of the association of Joubert's syndrome and Leber's amaurosis within a sibship affecting both sexes, ${ }^{15}$ its occurrence in a consanguineous mating, ${ }^{15}$ and its concordance in monozygous twins (present report) suggests autosomal recessive inheritance and suggests that unless there is close genetic linkage both anomalies are due to a single gene defect.

We thank Dr Angus Gibson, Dr David Doyle, and Professor William Lee respectively for general, neurological, and ophthalmological pathology; Dr Mark Ziervogel for cerebral ultrasonography and the Department of Medical Illustration, Yorkhill Hospital for preparation of the manuscript.

\section{References}

I Joubert M, Eisenring J, Robb JP, Andermann F. Familial agenesis of the cerebellar vermis. Neurology 1969;19:813-25.

2 Santolaya JM, Pascual-Castroviejo I. Defectos Vermianos; retraso mental; movimientos anormales y alteraciones del ritmo respiratorio. Rev Neurol (Spain) 1974;2:15-24.

${ }^{3}$ Boltshauser E, Isler W. Joubert syndrome: episodic hyperpnoea, anormal eye movements retardation and ataxia, associated with dysplasia of the cerebellar vermis. Neuropediatrie 1977;8:57-66.

${ }^{4}$ Calogero JA. Vermian agenesis and unsegmented midbrain tectum. J Neurosurg 1977;47:605-8.

5 Tomita H, Ohno K, Tamai A. Joubert syndrome associated with Leber's congenital amaurosis. (in Japanese). Brain Dev 1979;11:459-65.
${ }^{6}$ Dralle D, Schmidt-Scommerfeld E. Zusammenhange zwischen atemregulation und paradoxen schlaf bei einem patienten mit Joubert syndrome. Klin Padiatr 1979;191:83-90.

7 Curatolo P, Mercuri S, Cotroneo E. Joubert syndrome: a case confirmed by computed tomography. Dev Med Child Neurol 1980;22:362-6.

${ }^{8}$ Lindhout D, Barth PG, Boen-Tan TN. The Joubert syndrome associated with bilateral chorioretinal coloboma. Eur J Paediatr 1980;134:173-6.

${ }^{9}$ Burroni M, Perrotta F, Rossolini V. Sindrome di Joubert. Minerva Pediatr 1980;32:763-6.

10 Aparicio-Meix JM. Pascual Castroviejo I. Sindrome de Joubert. Estudio de un neuvo caso y revision de la literatura. An Esp Pediatr 1980;13:625-32.

1 Boltshauser E, Deonna T, Despland PA, Lange B, De Meuron G. Joubert syndrome: three new cases. Neuropediatrics 1981;12: (Suppl) 439.

12 Boltshauser E, Herden M, Dumermuth G, Isler W. Joubert syndrome: clinical and polygraphic observations in a further case. Neuropediatrics 1981;12:181-91.

13 Egger J, Bellman M, Ross EM, Baraister M. JoubertBoltshauser syndrome with polydactyly in siblings. $J$ Neurol Neurosurg Psychiatry 1982;45:737-9.

${ }^{14}$ Suzuki H, Nakazato A, Hiroko I, et al. A case of Joubert syndrome-CT findings of brainstem and review of literature. (in Japanese). Brain Dev 1983;15:67-73.

15 Aicardi J, Castello-Branco M, Roy C. Le syndrome de Joubert. A propos de cinq observations. Arch Fr Pediatr 1983;40:625.

16 Friede RL, Boltshauser E. Uncommon syndromes of cerebellar vermis aplasia. 1: Joubert syndrome. Dev Med Child Neurol 1978;20:758-63

17 Vaizey MJ, Sanders MD, Wybar KC, Wilson J. Neurological abnormalities in congenital amaurosis of Leber. Arch Dis Child 1977:52:399-402.

${ }^{18}$ Noble KG, Carr RE. Leber's congenital amaurosis. A retrospective study of 33 cases and a histopathological study of one case. Arch Ophthalmol 1978;96:818-21.

${ }^{19}$ Kroll AJ, Kuwabara T. Electron microscopy of a retina abiotrophy. Arch Ophthalmol 1964;71:683-90.

${ }^{201}$ Mizuno K, Takei Y, Sears ML. Leber's congenital amaurosis. Am J Ophthalmol 1977;83:32-42.

${ }^{21}$ Francois J, Hannsens M. Examen histopathologique de deux cas de degenerescence tapeto-retinienne congenitale de Leber. Ann Oculist (Paris) 1969;202:127-55.

22 Sorsby A, Williams CE. Retinal aplasia as a clinical entity. $\mathrm{Br}$ Med J 1960;i:293-7.

${ }^{23}$ Gillespie FD. Congenital amaurosis of Leber. Am J Ophthalmol 1966;61:874-80.

${ }^{24}$ Hsia YE, Bratu M, Herbordt A. Genetics of the Meckel syndrome. Dysencephalia splanchocystica. Pediatrics 1971;48:237-47.

25 Fried K, Liban E, Lurie M, Friedman S, Reisner SH. Polycystic kidneys associated with malformations of the brain, polydactyly and other birth defects in newborn sibs. J Med Genet 1971:8:285-90.

${ }^{26}$ Gustavson KH, Kreuger A, Petersson PO. Syndrome characterised by lingual malformation polydactyly, tachypnoea and psychomotor retardation (Mohr syndrome). Clin Genet 1971:2:261-6.

27 D'Agostino AN, Kernohan JW. The Dandy-Walker syndrome. $J$ Neuropathol Exp Neurol 1963;22:450-70.

${ }^{28}$ Gardner E, O'Rahilly R, Prolo D. The Dandy-Walker and Arnold-Chiari malformations. Arch Neurol 1975;32:393-407.

${ }^{29} \mathrm{Kreiger} \mathrm{A}$, Detiviler J, Trooskin B. Respiration in an infant with the Dandy-Walker syndrome. Neurology 1974;24:1064-7.

3) Pagon RA, Chandler J, Collie WR, et al. Hydrocephalus, agyria, retinal dysplasia, encephalocele (HARD \pm E) syndrome: an autosomal recessive condition. Birth Defects 1978:XIV:233-41. 


\section{King, Dudgeon, and Stephenson}

${ }^{31}$ Zetterstrom B. The electroretinogram of the newborn infant. Proceedings of the 8th ISCERG Symposium. Pisa 1971; 1.

${ }^{32}$ Horsten GPM, Winkleman JE. Development of the ERG in relation to histological differentiation of the retina in man and animals. Arch Ophthalmol 1960;63:232-42.

${ }^{33}$ Bhupathy K, Sethupathy R, Pildes R, Constantaras A, Fourmer $\mathrm{J}$. Electroretinography in neonates with phototherapy. Pediatrics 1978;61:189-92.

${ }^{34}$ Schapper-Kimmijser J, Henkes HE, Bosch Van Den J. Amaurosis congenita (Leber). Arch Ophthalmol 1959;61:211-8.

35 Dekeban A, Carr R. Congenital amaurosis of retinal origin. Arch Neurol 1966;14:294-301.

${ }^{36}$ Dekeban A. Hereditary syndrome of congenital retinal blindness (Leber), polycystic kidneys and maldevelopment of the brain. Am J Ophthalmol 1969;68:1029-37.
37 Dekeban A. Mental retardation and neurologic involvement in patients with congenital retinal blindness. Dev Med Child Neurol 1972;14:436-44.

${ }^{38}$ Mercuri S, Curatolo P, Giuffre R, Di Lorenzo N. Agenesis of the vermis cerebelli and malformation of the posterior fossa in childhood and adolescence. Neurochirugia 1979:22:180-8.

${ }^{39}$ Hamilton WJ, Mossman HW. Human embryology. 4th ed. London: MacMillan, 1972.

41) Spira AW, Hollenberg MJ. Human retinal development: ultrastructure of the inner retinal layers. Dev Biol 1973;31:1-21.

Correspondence to Dr J B P Stephenson, Fraser of Allander Unit, Royal Hospital for Sick Children, Yorkhill, Glasgow G3 8SJ.

Received 27 April 1984 